\title{
Basal Cell Adenoma in the Parotid Gland: A Case Report of Rare Salivary Gland Tumor
}

\author{
Chonji Fukumoto*, Kazuya Hiroshima, Toshihide Watanabe \\ Department of Dental and Oral Surgery, Kimitsu Chuo Hospital, 1010 Sakurai, Kisarazu, Chiba 292-8535, Japan
}

Copyright $\bigcirc 2017$ by authors, all rights reserved. Authors agree that this article remains permanently open access under the terms of the Creative Commons Attribution License 4.0 International License

\begin{abstract}
Salivary gland tumors are rare and constitute about 2 to $6.5 \%$ of all head and neck neoplasms. Basal cell adenoma (BCA) is a rare benign tumor in salivary gland, accounting for 1 to $3 \%$ of all salivary gland tumors. Histopathologically, BCA is composed of basaloid cells and can be classified into solid with most common type, trabecular, tubular, and membranous types. It is mainly found in the parotid gland, and it is commonly treated via a parotidectomy. In this study, we report a case of surgical excision trabecular-tubular mixed type BCA in the surface of the parotid gland, with preservation of the facial nerve and body of the parotid gland.
\end{abstract}

Keywords Salivary Gland Tumor, Basal Cell Adenoma, Parotid Gland, Facial Nerve Preservation

\section{Introduction}

Salivary gland tumors are uncommon and constitute about 2 to $6.5 \%$ of all head and neck neoplasms. Basal cell adenoma (BCA), a rare benign tumor in salivary gland, accounts for 1 to $3 \%$ of all salivary gland tumors [1-3]. BCA was first reported by Kleinsasser and Klein [4] in 1967 and was later described as a separate salivary gland tumor in the 1991 WHO classification. BCA has been classified into four histological types: solid, trabecular, tubular, and membranous types [3,5]. Its most frequent location is the parotid gland, and a parotidectomy is commonly performed. Here, we report a case of surgical excision trabecular-tubular mixed type BCA in the surface of the parotid gland, with preservation of the facial nerve and body of the parotid gland.

\section{Case Presentation}

A 44-year-old woman presented to the Division of Dental and Oral Surgery, Kimitsu Chuo Hospital, with a history of painless swelling in her right cheek. The mass slowly increased in size and became asymptomatic. Facial examination revealed a well-circumscribed elastic, hard, and movable mass in the right malar region measuring approximately $25 \mathrm{~mm}$ in diameter (Figure 1). There was no palpable lymph node in the neck region, and facial nerve function was intact. She had no relevant medical history.
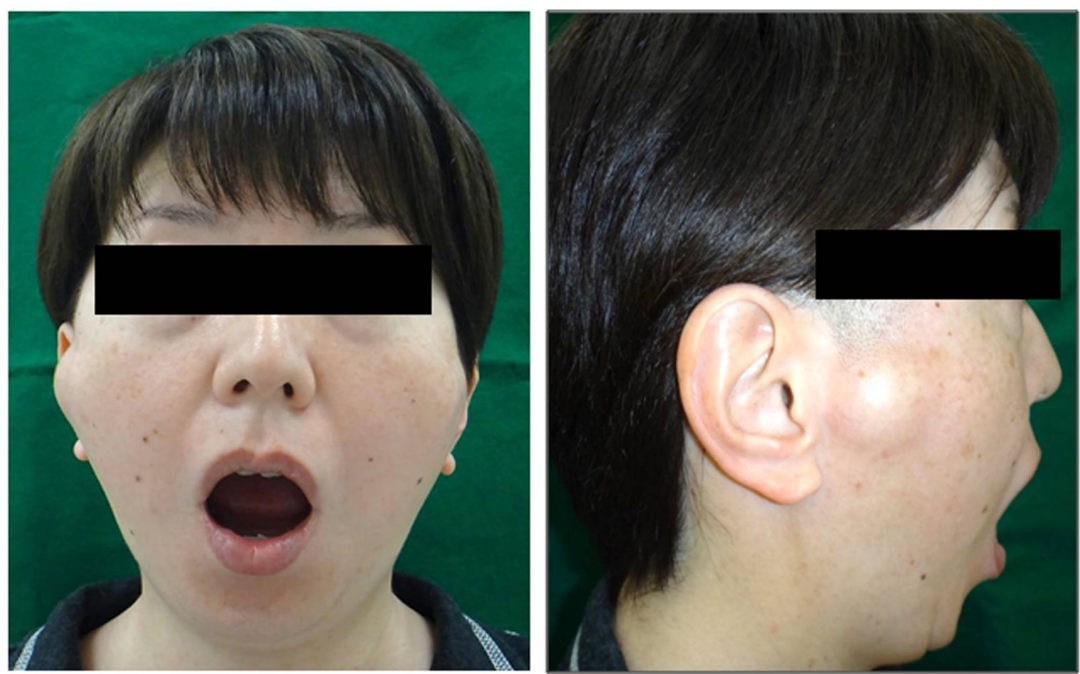

Figure 1. Facial preoperative view 

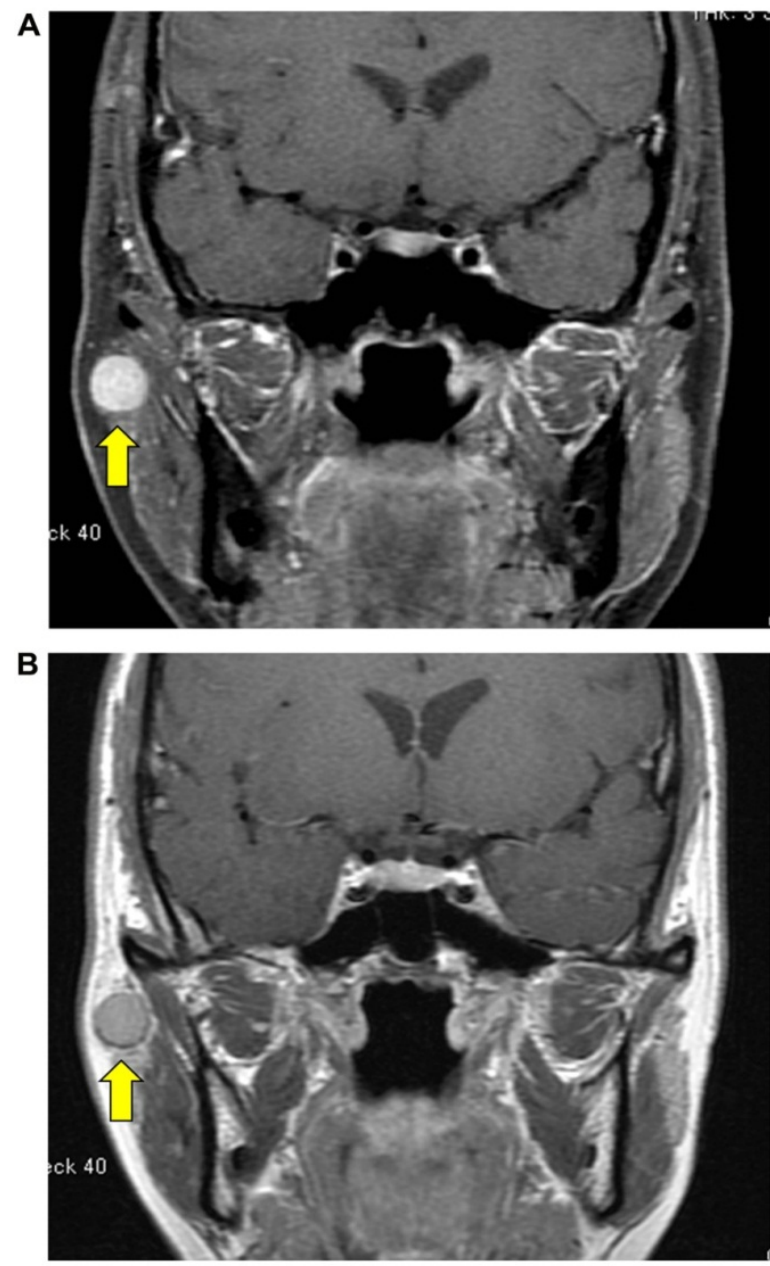

Figure 2. Gd-DTPA enhanced MRI sequence (A) T1-weighted, (B) fat suppression T1-weighted

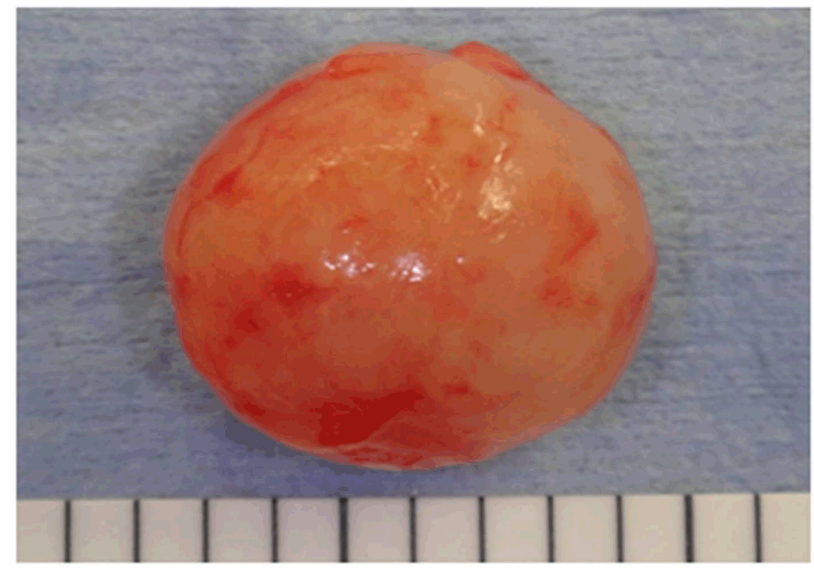

Figure 4. Surgical specimen

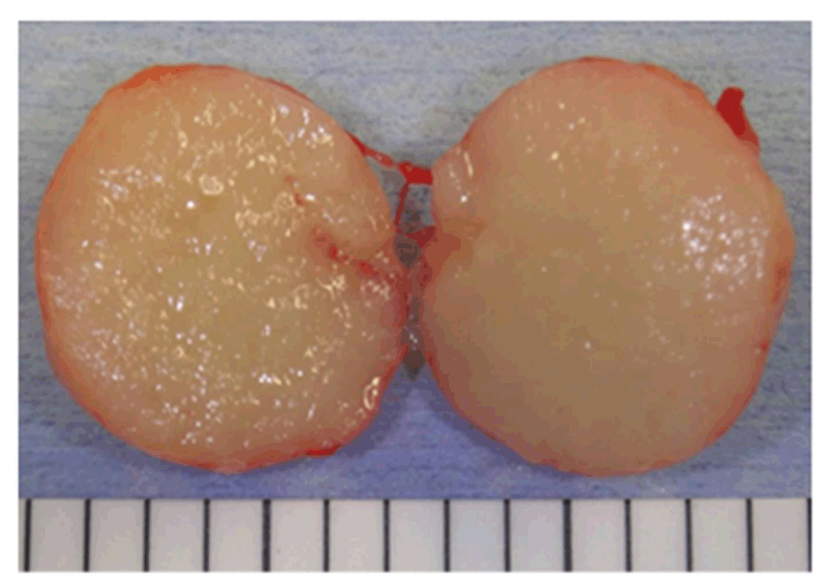

On further diagnosis, the Gd-DTPA-enhanced magnetic resonance imaging (MRI) showed a well-defined round mass with moderate signal intensity on the T1-weighted image (Figure 2A) and high signal intensity on fat suppression T1-weighted image (Figure 2B) in the superficial part of right parotid. The clinical diagnosis was suspected to be a benign tumor arising in the superficial portion of the parotid gland.

An excisional biopsy was performed under general anesthesia for further confirmation. The tumor was surrounded by a thin capsule and was removed with preservation of the facial nerve and no excision of the body of the parotid gland (Figure 3). The enucleation was relatively easy due to the lack of adhesions between the tumor and the parotid gland. Macroscopically, the spherical surgical specimen was measured to be $13 \times 13 \times 12 \mathrm{~mm}$ and encapsulated by a thin fibrous tissue (Figure 4 ).

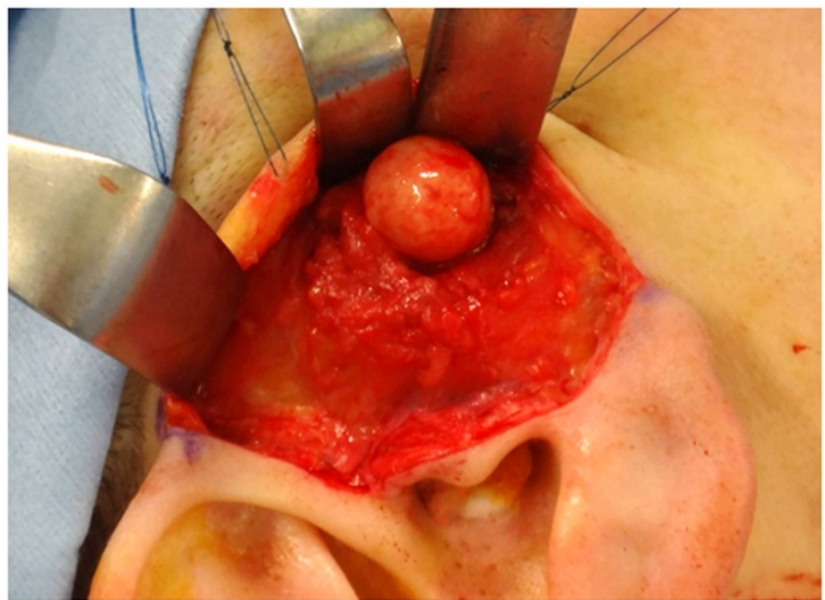

Figure 3. Intra-operative appearance of tumor mass 

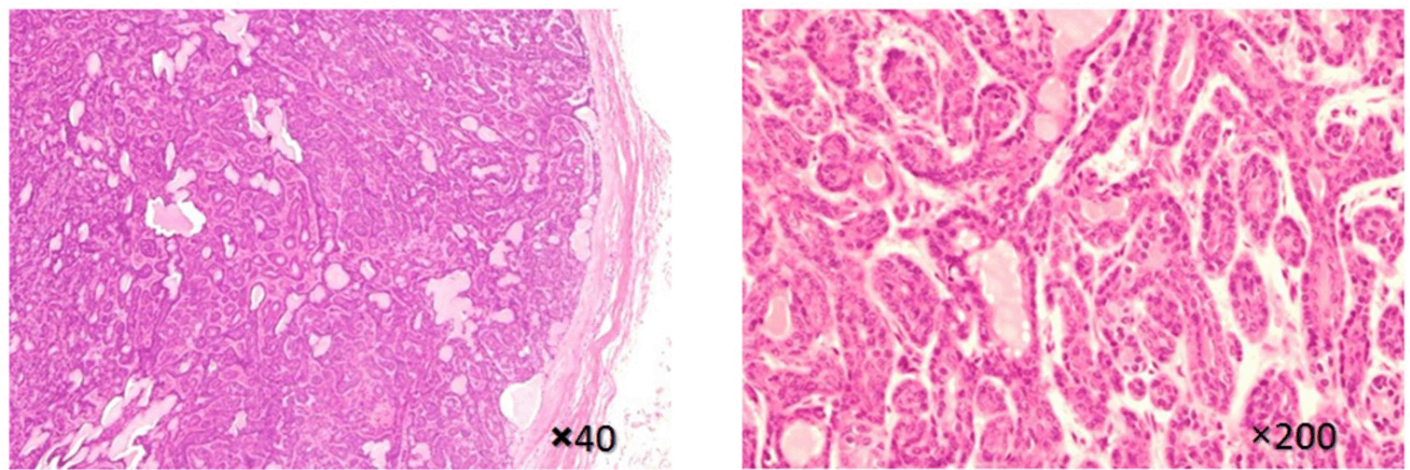

Figure 5. Histopathologic section (hematoxylin and eosin stain
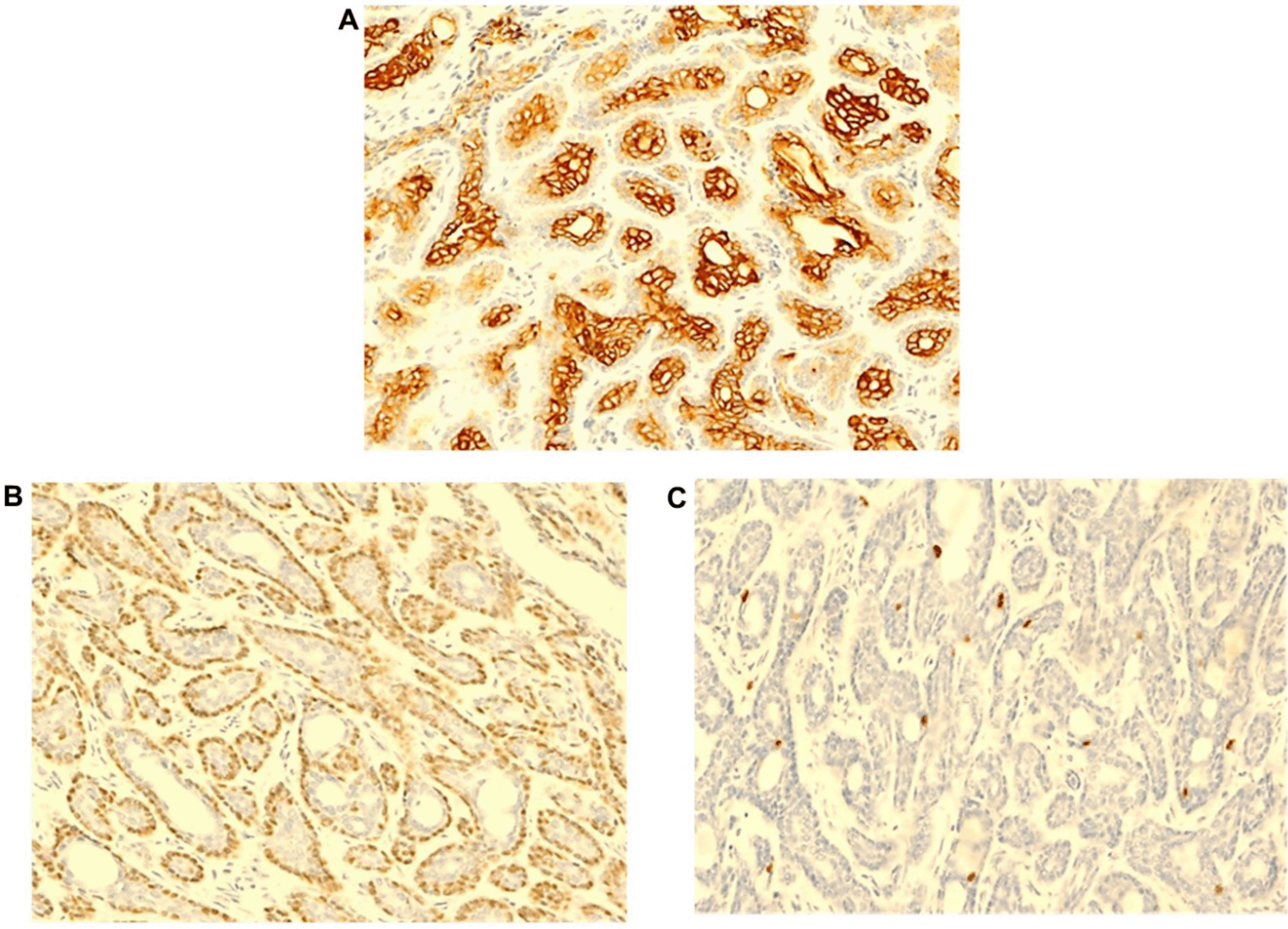

Figure 6. Immunohistochemical staining with (A) Cytokeratin AE1/AE3, (B) p63, (C) MIB-1 (Ki-67)

The histopathological examination of the section stained with hematoxylin \& eosin showed the proliferation of basaloid cells with trabecular and tubular patterns and a peripheral layer of cells (Figure 5). No mitotic activity, necrosis, or nuclear pleomorphism was noticed in the tumor. Immunohistochemically, the inner cells of tubular structures were strongly positive for Cytokeratin (CK) AE1/AE3 (Figure 6A), and the nuclear of the outer cells were positive for p63 (Figure 6B). The MIB-1 (Ki-67) labeling index was extremely low, i.e., $2.5 \%$ (Figure $6 \mathrm{C}$ ). On the basis of these features, the final diagnosis was confirmed as trabecular-tubular mixed type BCA.

\section{Discussion}

Previously, BCA was considered to be a type of "monomorphic adenoma" [4]. However, the name of this tumor has been changed to "BCA" in the WHO salivary gland tumor classification since 1991. The most frequent location of BCA is the parotid gland (75\%), followed by the minor salivary gland from the upper lip with $6 \%$, and submandibular gland with 5\% [6-8]. Clinically, BCA frequently occurs in people aged more than 50 years as a unilateral tumor with round or oval swelling. This tumor tends to be an asymptomatic, slowly growing and movable mass with a maximum diameter of $3 \mathrm{~cm}[9,10]$.

Histopathologically, BCA is composed of basaloid cells, classified based on their morphologic pattern into four subtypes: solid with most common type, trabecular, tubular, and membranous [5]. The recurrence and malignant transformation are more common in the membranous type than in other subtypes $[9,11,12]$. In the present case, the tumor was histopathologically classified as tubular-trabecular mixed type BCA.

The differential diagnoses of $\mathrm{BCA}$ are pleomorphic 
adenoma (PA), adenoid cystic carcinoma (ACC), and basaloid cell adenocarcinoma (BCAC). BCA has no rich stroma and the myxoid or chondroid elements as characteristics of PA $[8,9,13]$. Although ACC and BCAC have clinical and histological similarities with BCA, these malignant tumors exhibit invasive, unencapsulated growth into adjacent soft tissue, often with associated vascular or perineural invasion [7-9]. In addition to cytology differences, the high MIB-1 (Ki-67) labeling index helps distinguish $\mathrm{ACC}$ and BCAC from BCA [8].

The primary treatment of BCA is surgical excision by means of a parotidectomy. In the present case, we performed local excision because the tumor existed in the superficial portion of the parotid gland and was easily detached from the parotid gland. The patient's condition was well without facial paralysis and free of disease at 3 years after the surgery.

\section{Conclusions}

In conclusion, we report a case of surgical excision trabecular-tubular mixed type $\mathrm{BCA}$ in the surface of the parotid gland, with preservation of the facial nerve and body of the parotid gland. Though regarded as rare, BCA should be kept in mind in the management of salivary gland tumors.

\section{Conflict of Interest}

The authors declare that there is no conflict of interests regarding the publication of this paper.

\section{REFERENCES}

[1] A. J. Chawla, T. Y. Tan, G. J. Tan. Basal cell adenoma of the parotid gland: CT scan features, European Journal of Radiology, Vol.58, No.2 260-265, 2006.

[2] R. Kawata, K. Yoshimura, K. Lee. Basal cell adenoma of the parotid gland: a clinicopathological study of nine cases-basal cell adenoma versus pleomorphic adenoma and Warthin's tumor, European Archives of Oto-Rhino-Laryngology, Vol. 267, No.5, 779-783, 2010.

[3] Y. Huang. Basal cell adenoma in the parotid: a bizarre myoepithelial-derived stroma rich variant, International Journal of Clinical and Experimental Pathology, Vol.7, No.7, 4512-4515, 2014.

[4] O. Kleinsasser, H. J. Klein. Basal cell adenoma of the salivary glands, Arch Klin Exp Ohren Nasen Kehlkopfheilkd, Vol.189, No.3, 302-316, 1967.

[5] R. R. Seethala, E. L. Barnes. Rare malignant and benign salivary gland epithelial tumors, Surgical Pathology Clinics, Vol. 4, No.4, 1217-1272, 2011.

[6] N. C. Chiu, H. M. Wu, Y. H. Chou, W. Y. Li, Y. Y. Chiou, W. Y. Guo, C. Y. Chang. Basal cell adenoma versus pleomorphic adenoma of the parotid gland: CT findings, American Journal of Roentgenology, Vol. 189, No.5, W254-261, 2007.

[7] V. Rajasenthil, A. Ravi. Basal Cell Adenoma of the Parotid Gland-A Rare Entity, Indian Journal of Surgery, Vol. 76, No.5, 408-410, 2014.

[8] M. Kudoh, H. Harada, Y. Sato, K. Omura, Y. Ishii. A case of Basal cell adenoma of the upper lip, Case Reports in Medicine, 2014: 795356, 2014

[9] P. N. Lambade, D. Rajkhokar, D. Lambade. Basal Cell Adenoma of Submandibular Salivary Gland: A Case Report and Literature Review, Journal of Maxillofacial and Oral Surgery, Vol.14, No.4, 999-1003, 2015.

[10] J. Lu, W. Zhang, Z. Wang, H. Jia, Y. Ma, H. Wu, M. Xiang. Basal cell adenoma of the parotid gland: clinical and pathological findings in 29 cases, International Journal of Clinical and Experimental Pathology, Vol.8, No.3, 2899-2908, 2015.

[11] M. Veeresh, R. M. Bavle, K. N. Vinay, H. Nandakumar. Basal cell adenoma of the submandibular gland, Journal of Maxillofacial and Oral Surgery, Vol. 9, No.3, 289-291, 2010.

[12] M. J. Jung, J. L. Roh, S. H. Choi, S. Y. Nam, S. Y. Kim, S. W. Lee, K. J. Cho. Basal cell adenocarcinoma of the salivary gland: a morphological and immunohistochemical comparison with basal cell adenoma with and without capsular invasion, Diagnostic Pathology, Vol.8, 171, 2013.

[13] JKuang, Q. Rao, H. Zhang, Z. Cheng. Synchronous unilateral basal cell adenoma of the parotid gland: A case report, Oncology Letters, Vol. 8, No.4, 1822-1824, 2014. 